\title{
Review of best practice in cardiac rehabilitation for women
}

Osaimi Alosaimi

Faculty of Rehabilitation Medicine, University of Alberta, Canada, alosaimi@ualberta.ca

Angelica N. Reyes MScOT

Faculty of Rehabilitation Medicine, University of Alberta, anreyes@ualberta.ca

Cary A. Brown PhD

Faculty of Rehabilitation Medicine, University of Alberta, cary.brown@ualberta.ca

Follow this and additional works at: https://nsuworks.nova.edu/ijahsp

Part of the Occupational Therapy Commons, and the Physical Therapy Commons

\section{Recommended Citation}

Alosaimi O, Reyes AN, Brown CA. Review of best practice in cardiac rehabilitation for women. The Internet Journal of Allied Health Sciences and Practice. 2017 Jan 01;15(3), Article 8.

This Manuscript is brought to you for free and open access by the College of Health Care Sciences at NSUWorks. It has been accepted for inclusion in Internet Journal of Allied Health Sciences and Practice by an authorized editor of NSUWorks. For more information, please contact nsuworks@nova.edu. 


\title{
Review of best practice in cardiac rehabilitation for women
}

\begin{abstract}
Purpose: Cardiovascular disease is defined as damage to, or narrowing of, arteries due to atherosclerosis and is the leading cause of mortality and morbidity among women worldwide. Cardiovascular disease is recognized to be both a leading cause of mortality and an undertreated condition for women. The goals of this review manuscript are to present the current background literature specific to cardiac rehabilitation programs for women and serve as a knowledge translation strategy to help raise therapists' awareness of the need for cardiac rehabilitation programs specifically designed for female patients. Methods: A review of best practice literature in cardiac rehabilitation for women. Results: With current increasing trends in risk factors, including stress, obesity, poor diet, smoking, and a sedentary lifestyle, the future burden could be overwhelming from the perspective of individuals' health and health authorities' resources. Conclusions: Emerging research clearly demonstrates the need for cardiac rehabilitation programs tailored for women and highlighting the unique features of program delivery that can reduce the risk of under-referral and treatment program dropout.
\end{abstract}

\section{Author Bio(s)}

Osaimi Alosaimi, BPT, is a physiotherapist and MSc student with diverse experience in cardiac rehabilitation.

Angelica Reyes, MScOT is a clinical occupational therapist/researcher with experience in a range of patient populations, currently working in Edmonton, Alberta.

Cary Brown, $\mathrm{PhD}$ is a professor in the Faculty of Rehabilitation Medicine, University of Alberta

\section{Acknowledgements}

We would to acknowledge Osaimi Alosaimi's sponsors for supporting his advanced studies in cardiac rehabilitation 


\title{
IITAHSP \\ The Internet Joưnal of Allied Health Sciences and Practice
}

Dedicated to allied health professional practice and education

Vol. 15 No. 3 ISSN 1540-580X

\section{Review of Best Practice in Cardiac Rehabilitation for Women}

\author{
Osaimi Alosaimi, BPT \\ Angelica N. Reyes, MScOT \\ Cary Brown, PhD \\ University of Alberta
}

Canada

\begin{abstract}
Purpose: Cardiovascular disease is defined as damage to, or narrowing of, arteries due to atherosclerosis and is the leading cause of mortality and morbidity among women worldwide. Cardiovascular disease is recognized to be both a leading cause of mortality and an undertreated condition for women. The goals of this review manuscript are to present the current background literature specific to cardiac rehabilitation programs for women and serve as a knowledge translation strategy to help raise therapists' awareness of the need for cardiac rehabilitation programs specifically designed for female patients. Methods: A review of best practice literature in cardiac rehabilitation for women. Results: With current increasing trends in risk factors, including stress, obesity, poor diet, smoking, and a sedentary lifestyle, the future burden could be overwhelming from the perspective of individuals' health and health authorities' resources. Conclusions: Emerging research clearly demonstrates the need for cardiac rehabilitation programs tailored for women and highlighting the unique features of program delivery that can reduce the risk of under-referral and treatment program dropout.
\end{abstract}

\section{BACKGROUND}

\section{Prevalence of Cardiovascular Disease in Women}

Cardiovascular disease (CVD) is a class of diseases that involve the damage to, or narrowing of, arteries due to atherosclerosis. ${ }^{1}$ Cardiovascular disease includes, but is not limited to myocardial infarct (MI), angina, atherosclerosclerotic disease, valvular disease, cardiomyopathy, hypertensive heart disease, heart failure, acute coronary syndrome, and asymptomatic coronary heart disease. ${ }^{1}$ Procedures related to CVD include coronary artery bypass graft, percutaneous coronary intervention, and cardiac valve repair. ${ }^{1}$ Although CVD is the leading cause of mortality and morbidity among women worldwide, CVD is a major health problem in developed nations as it is the primary cause of morbidity, mortality, and low quality of life in Canada, the United States (US), and Europe. ${ }^{2-4}$ CVD is a leading cause of death for many women in the US and other western countries. ${ }^{5}$ Statistics have shown that CVD declined in the US by 29.2\% from 1996 to 2006. During 2006, 433,000 women in the US were affected with CVD, which constitutes a larger number compared to other serious health problems, such as respiratory diseases, cancer, Alzheimer's, and accidents. ${ }^{6,7}$

CVD has demographic and regional differences that stem from hospitalization and treatment methods as well as variability in risk factors. ${ }^{4}$ The Public Health Agency of Canada (2009) statistics indicate that in 2007, the incidence of heart disease was $2.7 \%$ and $6.4 \%$ in the Northwest Territories and Nova Scotia, respectively. Eastern Canada was found to have a higher prevalence of CVD compared to northern and western regions. Ethnicity also plays a role. ${ }^{4}$ For example, CVD in Canada has been found to be highly prevalent among South Asian, African-Caribbean, and Aboriginal patients, who are at higher risk of morbidity and mortality compared to those of European origin. ${ }^{8}$

For the past three decades, the CVD mortality rate in the United States has been higher for women than for men. ${ }^{9}$ In Canada, CVD is the second leading cause of death among women, at the rate of 2.4 and 3,082.8 per 100,000 in those aged 25 to 34 , and 85 years or more, respectively. ${ }^{4}$ With current increasing trends in risk factors which include stress, obesity, poor diet,

(c) The Internet Journal of Allied Health Sciences and Practice, 2017 
smoking, and a sedentary lifestyle, the future burden could be overwhelming from the perspective of individuals' health and governments' budgets.

\section{CVD Risk Factors in Women}

There are several risk factors of CVD identified in the literature. These include being post-menopausal, age, obesity, smoking, heredity, hyperlipidemia, sedentary lifestyle, diabetes, stress, and hypertension. ${ }^{6}$ Gender-specific research highlights the necessity to conduct more studies that focus on gender differences with respect to pathophysiology, clinical presentation, and outcomes. $^{9-11}$ With respect to risk factors, studies suggest that some are more prominent among women than men. These include hypertension, type 2 diabetes mellitus (DM), depression, and psychosocial factors. ${ }^{12,13}$

Hypertension is more prevalent in women than in men over 65 years of age and is significantly associated with $\mathrm{Ml}$ in women. ${ }^{14}$ Cardiac death increases 3-fold in women with systolic blood pressure levels greater than $185 \mathrm{~mm} / \mathrm{Hg}$ compared to those at or below $135 \mathrm{~mm} / \mathrm{Hg}$. Evidence shows that women with Type 2 DM are at higher risk of CVD death than men with Type 2 DM. ${ }^{15,16}$ $\mathrm{DM}$ is considered a strong risk factor in young women, where it increases their chances of coronary heart disease 4- to 5 -fold. ${ }^{17}$ In addition, high levels of total cholesterol and low-density lipoprotein (LDL) cholesterol are considered to be risks for cardiac death in middle-aged $(<65)$ and elderly $(>65)$ women. ${ }^{18} \mathrm{~A}$ study of 32,826 postmenopausal women found that high-density lipoprotein (HDL) cholesterol eliminated the high risk of chronic heart disease. ${ }^{19}$ Estrogen levels also may play a role because as women reach menopause, their LDL levels increase significantly. ${ }^{20}$

Depression is almost two times more prevalent in women than in men in the general population and has been shown to elevate women's risk for $\mathrm{Ml}$ and cardiac-related death by at least 50\%. ${ }^{12,21,22}$ Depression is also linked to cardiac death in middle-aged and elderly women. ${ }^{23}$ Additionally, stress derived from home, work, and major life events have been shown to be a risk factor for $\mathrm{Ml}$ in women as demonstrated by a study reporting higher perceived stress scores among young women with Ml compared to young men with Ml.14,24 Furthermore, Albert et al followed 121,701 women aged 30 to 55 years, between the years 19761998 and observed 224 cardiac-related deaths. ${ }^{25}$ They concluded that the risk of cardiac arrest increases as women age. Sixtynine percent of women in the study with sudden cardiac death were reported to lack a prior history of cardiac disease. However, $94 \%$ of them reported one or more risks factors, including smoking, diabetes, and hypertension. ${ }^{25}$

\section{CARDIAC REHABILITATION AND CVD}

Cardiac Rehabilitation (CR) is a comprehensive service that entails medical assessment, prescription, modification of cardiac disease risk factors, education, and counseling. ${ }^{26}$ The goal of $C R$ is to relieve cardiac symptoms, improve patients' physical function, and increase their quality of life. CR usually consists of four phases beginning with the patient's hospitalization following an acute cardiac incident (Phase I), followed by Phases II-IV which include ongoing and specific assessment, in-clinic interventions, and home programs for long-term cardiac health. ${ }^{27}$ The importance of CR programs as preventive strategies in cardiovascular incident recurrence is acknowledged and endorsed globally. ${ }^{28-30}$

\section{Cardiac Rehabilitation Program Components}

Balady et al have highlighted various components of CR programs designed to reduce CVD-related risk factors, improve quality of life and physical function, and prevent future cases of CVD. ${ }^{26}$ These components include exercise prescription, diet counseling, body lipid pharmacological management, physical examination including blood pressure, weight and body mass index (BMI), medical history review, evaluation and education programs for comorbid diabetes and other chronic health conditions, evaluation and treatment of psychological and social problems, and programs to address smoking and addictions. Additionally, the consensus statements of the American Heart Association, American Association of Cardiovascular and Pulmonary Rehabilitation, and the Agency for Health Care Policy and Research underscore that CR programs should offer a multidisciplinary approach to achieve CVD risk reduction and that programs consisting of exercise training alone are not considered CR. $28,31,33$

\section{Benefits of Cardiac Rehabilitation}

Empirical studies illustrate that $C R$ programs provide extensive benefits to eligible populations. ${ }^{6}$ These benefits include improvement in physical capacity, cardiovascular profile (e.g., lipids, blood pressure, and diabetes), depression, anxiety, quality of life, and weight reduction, in addition to reductions in morbidity and mortality rates, hospital readmissions, and psychological disorders. ${ }^{34}$ Studies also have shown that women derive the same benefits as do men. ${ }^{35}$

Exercise is considered the cornerstone of CR programs. Oldridge's review of six independent, exercise-based CR metaanalyses, published since 2002, included 71 randomized clinical trials with a total of 13,824 participants. ${ }^{36}$ The findings revealed significantly positive outcomes related to reductions in cardiac mortality, nonfatal re-infarction, and hospitalization rates, as well as favorable changes in total cholesterol, triglycerides, and systolic blood pressure. Another recent Cochrane systematic review and meta-analysis of the effectiveness of exercise-based CR included a total of 63 studies with 14,486 participants It showed

(c) The Internet Journal of Allied Health Sciences and Practice, 2017 
that exercise-based CR reduced cardiovascular mortality, hospital readmission, and contributed to major improvements in quality of life. ${ }^{37} \mathrm{~A}$ further 2016 meta-analysis investigated the effect of exercise on high sensitive c-reaction protein (hsCRP). This metaanalysis included 43 studies with 3,575 participants. It concluded that exercise interventions contributed to reductions in hsCRP levels in healthy adults and adults with CVD. ${ }^{38}$ Moreover, exercise training reduces clinical depression, anxiety, and hostility among patients with CVD. $39-41$

Other components of CR programs include education and psychological interventions. Brown et al. conducted a systematic review of 13 studies and 68, 556 participant that examined the effects of cardiac psycho-educational programs as a primary intervention versus typical care on morbidity, mortality, quality of life, and health costs. ${ }^{42}$ The authors reported that, while there was no strong evidence that psycho-educational programs as a primary intervention contributes to reductions in morbidity or mortality, there is evidence to support that they improve quality of life and reduce health care costs. Similarly, Whalley et al. ${ }^{43}$ carried out a systematic review of the independent effect of psychological interventions on CVD-related morbidity, mortality, quality of life, and psychological outcomes. A total of 24 studies and 9,296 participants were included. The authors concluded that, while there was no clear evidence of a positive effect of psychological interventions on morbidity, mortality, and quality of life, there was a slight to moderate improvement in depression and anxiety. ${ }^{43}$

Overall, CR offers patients a long-term program of medical evaluation, prescribed exercise, cardiac risk factor modification, education, and counseling. ${ }^{33} \mathrm{CR}$ has shown to improve survival rate, quality of life, functional status/aerobic fitness, cardiovascular risk profile, psychological status, and reduce hospital readmissions. ${ }^{34,44}$ Cardiac rehabilitation is also considered cost effective. 45,46

\section{CARDIAC REHABILITATION AND WOMEN}

Despite the numerous benefits previously described, evidence shows that with respect to referral, participation, and adherence, $\mathrm{CR}$ is generally underutilized by all patients, and most markedly in women. ${ }^{47-50}$ According to a study by Colella et al, which examined sex differences in referral to CR, the referral rate to CR for women was almost $10 \%$ lower than for men. ${ }^{48}$ In accordance with these findings, a subsequent retrospective cohort study that included 25,958 participants $(24.6 \%$ women) also revealed lower CR referral rates for women compared to men (31.1\% vs. $42.2 \%) .{ }^{47}$ As for women's enrollment in CR, a metaanalysis included 26 observational studies conducted between 2000 and 2011 with 797,719 participants (43.2\% women) showed that women were $36 \%$ less likely to be enrolled in CR programs. ${ }^{50}$ Moreover, evidence shows that after enrollment, women appear to have lower adherence to CR compared to men. A recent meta-analysis that investigated sex differences in adherence included 14 studies and 8,176 participants (27.3\% women) and concluded that some gender-based differences do exist in adherence to $\mathrm{CR}$, in that after enrollment, adherence to the prescribed sessions was $64.2 \%$ and $68.6 \%$ in women and men, respectively. ${ }^{49}$

\section{Barriers to Women's Use of Cardiac Rehabilitation}

Barriers that hinder eligible women from participating in, and adhering to, CR programs are categorized as: 1) patients' behavior/beliefs, 2) attitudes of health professionals (e.g., physicians/nurses/physiotherapists, etc.), and 3) contextual factors such as employment, self-esteem, family support, and transportation. ${ }^{27,28,51,52}$ Barriers attributable to patients' behavior/beliefs include: smoking, sedentary lifestyle, obesity, marital status, perceived program characteristics and suitability, anxiety, perceived self-efficacy and self-esteem, and perceptions that exercise is painful. ${ }^{51-61}$

Low rates of physician referrals and $\mathrm{CR}$ endorsement are also principal barriers contributing to low participation and adherence among women. ${ }^{48,61-63}$ Contextual factors that contribute to low participation in, and adherence to, $C R$ include age, gender roles such as primary caregiver and mother, low socioeconomic status, lack of transportation, low social support, and comorbidities such as depression and musculoskeletal limitations. $48-50,52-54,57,58,60-72$

\section{STRATEGIES TO ENHANCE WOMEN'S USE OF CARDIAC REHABILITATION}

Although $C R$ has been proven to be a beneficial and safe method of secondary prevention, it is often underutilized for women with CVD. 66 Many strategies have been proposed in attempts to overcome the multifactorial obstacles that hinder women's use of $\mathrm{CR}$ and to increase referrals to, enrollment in, and adherence to CR. ${ }^{73}$ These strategies will be explored in the following section.

\section{Referral Strategies to Enhance Enrollment in Cardiac Rehabilitation}

Inadequate referral of eligible female patients is one of the primary factors in low participation in CR. ${ }^{48}$ Automatic referral has been proposed to avoid referral gender bias. ${ }^{74}$ Automatic, system generated, referral is defined as the implementation of standing referral orders to $C R$ based on eligible diagnoses supported by clinical guidelines without requiring the physician to generate a referral for each specific patient. ${ }^{75}$ However, simply initiating a referral does not guarantee participation in CR. ${ }^{76,77}$ The joint policy statement of the Canadian Association of Cardiac Rehabilitation and Canadian Cardiovascular Society, based

(c) The Internet Journal of Allied Health Sciences and Practice, 2017 
on a synthesis of data available in the literature recommends using multiple referral strategies to enhance participation in CR. ${ }^{78}$ A systematic review and meta-analysis were carried out on 14 studies published prior to 2009. This review examined various referral strategies including usual referrals, system generated referrals, a liaison strategy, and other strategies (providing patients with educational materials and motivational letters). The studies included reported that enrollment following these referral strategies ranged from $6 \%$ to $32 \%$ for usual referral, $19 \%$ to $54 \%$ for system-generated referral, $35 \%$ to $56 \%$ for liaison strategy, $53 \%$ to $78 \%$ for the combination of system generated and liaison strategy, and $58 \%$ to $86 \%$ for system generated or liaison strategy combined with patient letters. The rate of enrollment in CR by referral strategy after the synthesis was $73 \%$ for patient letters, $66 \%$ for combined system generated and liaison strategy, $45 \%$ for system generated alone, and $44 \%$ for liaison strategy alone. ${ }^{78}$

\section{Alternative Models to Traditional, Hospital-based Cardiac Rehabilitation Programs}

To overcome or eliminate barriers that affect female patients' participation and adherence to CR programs, alternative models to hospital-based CR have been promoted. These alternative models include community, home, internet, and telephone-based CR programs. ${ }^{79}$ According to Dalal et al, home and community-based programs are structured programs that include monitoring and follow-up visits. ${ }^{80}$ Nurses can provide home-based programs to monitor and supervise the care and progress of their patients or ensure that healthcare is provided. ${ }^{31}$ Internet and telehealth-based programs that use information technologies help reach patients in remote areas and ensure modification of risk factors, education, guidance, and instruction in physical activities. ${ }^{79,81}$ These alternative models have yielded clinical outcomes as favorable as those achieved by hospital-based CR programs. A meta-analysis of 17 trials including 2,172 male and female participants concluded that home and hospital-based CR were equally effective in the clinical and health quality of life-related outcomes. ${ }^{82}$ Rawstorn et al conducted a meta-analysis to investigate the relative effectiveness of telehealth and hospital-based programs. A total of 11 trials that included 1,189 participants showed that telehealth CR programs were at least as effective as those based in hospitals with respect to clinical outcomes such as cardiovascular risk management and functional capacity. ${ }^{81}$

With the dramatic evolution in technology, Smartphone applications may offer an alternative and inexpensive model to deliver $\mathrm{CR}$ that integrates monitoring, education, language translation, and motivational features. However, this technology will require collaboration on the part of health professionals, researchers, and apps developers to exploit apps' advantages in providing credible, evidence-based health content. 83 Some of this work has begun. For example, Varnfield et al conducted a non-blinded, randomized controlled trial that included 120 post-Ml participants to compare the outcome of Smartphone-based home-CR versus traditional center-based CR on program for improved program adherence and other health-related metrics. ${ }^{84}$ Varnfield et al found that Smartphone-based CR showed better uptake and adherence outcomes than did traditional CR and yielded physiological, psychological, and quality of life outcomes as effective as those of traditional CR. ${ }^{84}$ Although the trial by Varnfield et al provided insight into the feasibility of Smartphone-based CR, large-scale randomized controlled trails (RCT) that examine a range of $\mathrm{CR}$ outcomes in various settings are required to draw solid conclusions about the effectiveness of Smartphone-based CR programs. $.84,85$

Even though the alternative models above support wider access to CR services and some patients prefer them to hospital-based programs, there is no specific, significant evidence of improvements in women's uptake and adherence, as women have been underrepresented notably in trials of alternatives. ${ }^{81,82,86}$

\section{Other Strategies}

A Cochrane systematic review by Karmali et al was conducted to examine interventions that reported enhanced uptake and adherence to $\mathrm{CR} \cdot{ }^{87} \mathrm{~A}$ total of $18 \mathrm{RCT}$ trials were included ( 10 studies that evaluated $\mathrm{CR}$ uptake and 8 that evaluated adherence). The authors reported that useful interventions included gender-tailored programs, structured follow-up via telephone call or visit by health professionals, intermediate phase programs, early referral to CR as a standing order in CVD management protocols, and motivational letters. With respect to adherence to $\mathrm{CR}$, interventions that showed improvement included action planning, goal setting, and activity monitoring through daily diary entries. ${ }^{87}$ However, women were notably underrepresented in these studies evaluating interventions to increase uptake and adherence to $C R$. In the past two decades, emerging evidence in the literature has suggested that gender-tailored $\mathrm{CR}$ programs may help overcome the barriers that prevent women from obtaining the optimal benefits of CR. However, only two studies were identified that focused specifically on women. ${ }^{88-92}$

The first study by Price was a RCT including 70 women that concluded a telephone-coaching strategy was effective in improving attendance in CR among women after hospital discharge. ${ }^{92}$ Despite the limited sample size, this study provides insight into the efficacy and feasibility of a telephone coaching strategy to enhance women's attendance in CR. ${ }^{22}$ Price's study was based on Social Cognitive Theory constructs of self-efficacy. ${ }^{92}$ Social Cognitive Theory regards human behavior as a dynamic reciprocal

(c) The Internet Journal of Allied Health Sciences and Practice, 2017 
relationship among three factors: behavior, personal (cognitive, affective, and biochemical), and socio-environmental. ${ }^{93}$ Cognitive personal factors include self-efficacy (i.e. an individual's confidence in performing a behavior or overcoming a barrier to behavior performance), and self-regulatory behavior (i.e. the ability to adjust behavior to achieve the desired results). ${ }^{94}$

A second study by Beckie proposed a motivational, enhanced, gender-tailored CR program for women (TCRP-W) including exercise, psycho-educational interventions guided by the Transtheoretical model (TMM) of behavior change, and motivational interviewing. ${ }^{95,} 96$ The TTM is considered to be a beneficial central organizing construct, as it guides the interventions by stage of change. Prochaska and Velicer propose that the TTM assists therapists in understanding and predicting how and when individuals will abandon high-risk behaviors and adopt healthy ones. ${ }^{96}$ This model integrates five stages of change: precontemplation, contemplation, preparation, action, and maintenance. The model involves constructs related to weighing pros versus cons in decision making, self-efficacy, and psychological influences on cognitive-behavioral change (e.g. experiential learning, consciousness raising, self-reflection, social norms, counterconditioning, helping relationships, reinforcement management, stimulus control, and self-management).

According to Prochaska and Velicer, individuals in the precontemplation stage deny the need to change their behavior because either they are unaware of its significant negative consequences or they have abandoned the idea of changing because they are demoralized. ${ }^{96}$ These individuals often become defensive and resistant if pressured to take action. Individuals in the precontemplation stage tend to believe that the difficulties outweigh the benefits of changing a behavior and are less confident that they can achieve their goal. In the transition from the precontemplation to the contemplation stage, their perception of the benefits increases and perception of the difficulties decreases. ${ }^{96}$

In contrast, individuals in the contemplation stage are more aware of the benefits of changing risky behaviors but they tend to overestimate the costs of doing so, which makes them ambivalent and unprepared to take action. In the preparation stage, the benefits begin to outweigh the difficulties and individuals have greater confidence that helps them take the action necessary to change their behavior. At this stage, individuals have decided to make a change and have begun to take steps towards their goal(s). Individuals in the action stage are engaged actively in changing their undesirable behaviors and developing healthy ones, while individuals in the maintenance stage have been able to sustain change and resist relapse for at least 6 months. ${ }^{96}$

Individuals' progress through the stages of behavior change occurs primarily in cyclic patterns as they may suffer relapses; however, the gains made prior to relapse are preserved and subsequent attempts to engage in action are more likely to be successful.98,99 In clinical settings, TTM expert system assessment can be used to assess individuals for multi-behavioral, staged-matched interventions. ${ }^{100}$ Beckie used the TTM expert system assessment to generate three computer reports (baseline, 3 , and 9 months) for each of three behaviors (healthy eating, physical activity, and stress management). ${ }^{95}$ The reports for each behavior are divided into sections with the first section focusing on the stage of change and readiness to change behavior. The second section explores pros and cons of changing. The third section provides participants with feedback relevant to their stage of change. The fourth section offers guidance on ways to enhance self-efficacy in difficult situations. The final section offers small, step-wise strategies to progress between stages..$^{95}$

A second key component guiding TCRP-W interventions is motivational interviewing. Motivational interviewing is defined as "a client-centered, directive method for enhancing intrinsic motivation by exploring and resolving ambivalence."97 The motivational interviewing philosophy is that the counselor should foster a collaboration with the patient and employ techniques designed to enhance the patient's willingness to change behavior and develop insight about what is intrinsically motivating to support desired changes. Expressing a sense of acceptance and empathy towards the patient is an overriding principle of motivational interviewing. A second principle is to help the patient realize the difference between present maladaptive behaviors and their coping style and the potential afforded by assuming adaptive and active coping behaviors. The key to developing intrinsic motivation is that the patient, not the counselor, assumes the primary role in identifying the reasons for positive action and lifestyle. The third principle concerns going with the flow of resistance. Attempting face-to-face arguments or other direct forms of persuasion is unproductive in overcoming any patient defensiveness and resistance to change. A final principle is to support the patient in developing a stronger sense of self-efficacy. The patient is acknowledged to be in charge of his or her own individual change. ${ }^{97}$

In the TCRP-W trials conducted by Beckie, each patient received three, 1-hour individualized face-to-face motivational interview sessions with a cardiovascular nurse specialist trained in behavioral intervention. ${ }^{95}$ The first took place before group exercises and psycho-educational sessions began. The second session began halfway through the study and the third occurred at the end of the study. The nurse helped the patients identify their maladaptive behaviors with respect to self-confidence, the importance of change, and readiness for change by guiding patients to recognize and articulate their mental arguments against

(c) The Internet Journal of Allied Health Sciences and Practice, 2017 
change. The nurse used non-judgmental behaviors and agreed that the patients had the right and ability to self-direct their own goals and facilitated their confidence to overcome barriers to reach their goals. ${ }^{95}$

According to Beckie, TTM and motivational interviewing principles and approaches were also used to guide the psychoeducational sessions. In those sessions, participants were first taught the TTM behavior change strategies and then offered evidence-based guidelines to help them practice the strategies of behavioral change. ${ }^{95}$ For example, in the contemplative stage, the TTM suggests that increasing emotional awareness is a useful intervention that can be accomplished by assigning the participant homework that includes strategies to enhance self-reevaluation and environmental reevaluation. The psychoeducational sessions discussed topics such as CVD risk factors, medications, communication skills, stress management, and dietary and exercise guidelines. The sessions were conducted in a group format that provided opportunities for social support, role-playing, and group brainstorming discussions that generated ideas to create positive change and allow each participant to hear new ideas and build new strategies. 95

Since introducing the TCRP-W approach, Beckie et al. have carried out rolling studies of the programs and concluded that, in comparison to traditional CR interventions, TCRP-W produces superior physiological and psychological outcomes.70,95,101 A significant shortcoming of the TCRP-W is that there appears to be no outcomes studies with this technique by researchers who are not aligned with Beckie et al.

\section{CONCLUSION}

As early as 1976, researchers identified that CVD program adherence and dropout were problematic. ${ }^{102}$ In the subsequent 50 years, we have learned that increasing women's access and participation in CR is complex. Access issues such as childcare, timing of programs when women are freer from domestic and paid work, and the problems with certain program equipment being too large and uncomfortable for women maybe just as important as the type of programming offered. Delivering rehabilitation via tele-link has been an option partially addressing these concerns for nearly two decades but is ineffective when used in isolation. ${ }^{103}$ Along with pharmaceutical interventions, CR is a key strategy in treatment and prevention of CVD which is the leading cause of morbidity and mortality among women worldwide. The bulk of the evidence in the literature demonstrates that $\mathrm{CR}$ contributes to significant improvement in physiological and psychological clinical outcomes. Despite this, studies have shown that there are barriers that lead women to underutilize CR. Alternative referral strategies (e.g., automatic referral), methods of delivery (e.g., home/community/internet-based CR), and modification of CR program components (e.g., follow-up visit with health professional) have addressed some of the system-created challenges. ${ }^{73}$ However, much work remains to be done to develop best-practice evidence for this high need and the growing area of women's health. As all stakeholders work toward this high level goal, clinicians can act within their own practices to identify opportunities in their CR interventions for female patients to reduce contextual barriers (e.g. transportation, childcare needs, cultural beliefs) and incorporate motivational interviewing and stages of change theory to build insight, motivation for change, and self-efficacy in a safe, non-judgmental environment.

\section{REFERENCES}

1. Lavie CJ, Thomas RJ, Squires RW, Allison TG, Milani RV. Exercise training and cardiac rehabilitation in primary and secondary prevention of coronary heart disease. Mayo Clin Proc. 2009;84(4):373-83. [PMCID: PMC2665984]

2. Gholizadeh L, Davidson P. More similarities than differences: An international comparison of CVD mortality and risk factors in women. Health Care Women Int. 2008;29(1):3-22. [PMID: 18176877]

3. Braig S, Peter R, Nagel G, Hermann S, Rohrmann S, Linseisen J. The impact of social status inconsistency on cardiovascular risk factors, myocardial infarction, and stroke in the EPIC-Heidelberg cohort. BMC Public Health. 2011;11(1):104-10. [PMID: 21324154]

4. Grace SL, Bennett S, Ardern Cl, Clark AM. Cardiac rehabilitation series: Canada. Prog Cardiovasc Dis. 2014;56(5):530-5. [PMCID: PMC4559456]

5. Dunderdale K, Thompson DR, Miles JN, Beer SF, Furze G. Quality-of-life measurement in chronic heart failure: Do we take account of the patient perspective? Eur J Heart Fail. 2005;7(4):572-82.

6. McCarthy MM, Vaughan Dickson V, Chyun D. Barriers to cardiac rehabilitation in women with cardiovascular disease: An integrative review. J Cardiovasc Nurs. 2011;26(5):1-10. [PMID: 21107274]

7. Lloyd-Jones D, Adams R, Carnethon M, De Simone G, Ferguson TB, et al. Heart disease and stroke statistics-2009 update a report from the American Heart Association Statistics Committee and Stroke Statistics Subcommittee. Circulation. 2009;119(3):e21-181. [PMID: 19171871]

8. Anand SS, Yusuf S, Vuksan V, Devanesen S, Teo KK, et al. Differences in risk factors, atherosclerosis, and cardiovascular disease between ethnic groups in Canada: The Study of Health Assessment and Risk in Ethnic groups (SHARE). Lancet. 2000;356(9226):279-84. [PMID:11071182]

9. Mozaffarian D, Benjamin EJ, Go AS, Arnett DK, Blaha MJ, et al. Heart disease and stroke statistics-2015 update: A report from the American Heart Association. Circulation. 2015;131(4):e29-322. [PMID: 25520374]

(c) The Internet Journal of Allied Health Sciences and Practice, 2017 
10. Wizemann TM, Pardue ML. (Eds.). Exploring the Biological Contributions to Human Health: Does Sex Matter? Washington, DC: National Academy Press; 2001.

11. Wenger NK. Gender disparity in cardiovascular disease: Bias or biology? Expert Rev Cardiovasc Ther. 2012;10(11):140111. [PMID: 23244361]

12. Mehta LS, Beckie TM, DeVon HA, Grines CL, Krumholz HM, et al. Acute myocardial infarction in women: A scientific statement from the American Heart Association. Circulation. 2016;133(9):916-47. [PMID: 26811316]

13. Shah T, Palaskas N, Ahmed A. An update on gender disparities in coronary heart disease care. Curr Atheroscler Rep. 2016;18(5):1-8. [PMID: 27029220]

14. Yusuf S, Hawken S, Ônpuu S, Dans T, Avezum A, et al. Effect of potentially modifiable risk factors associated with myocardial infarction in 52 countries (the INTERHEART study): Case-control study. Lancet. 2004;364(9438):937-52. [PMID: 15364185]

15. van der Giezen AM, van Kessel JG, Schopman-Geurts van Kessel JG, Schouten EG, Slotboom BJ, Kok FJ, Collette HJ. Systolic blood pressure and cardiovascular mortality among 13,740 Dutch women. Prev Med. 1990;19(4):456-65. [PMID: 2399226]

16. Bushnell C, McCullough LD, Awad IA, Chireau MV, Fedder WN, et al. Guidelines for the prevention of stroke in women: A statement for healthcare professionals from the American Heart Association/American Stroke Association. Stroke. 2014;45(5):1545-88. [PMID: 24503673]

17. Kalyani RR, Lazo M, Ouyang P, Turkbey E, Chevalier K, et al. Sex differences in diabetes and risk of incident coronary artery disease in healthy young and middle-aged adults. Diabetes Care. 2014;37(3):830-8. [PMID: 24178997]

18. Manolio TA, Pearson TA, Wenger NK, Barrett-Connor E, Payne GH, Harlan WR. Cholesterol and heart disease in older persons and women: Review of an NHLBI workshop. Ann Epidemiol. 1992;2(1):161-76. [PMID: 1342259]

19. Shai I, Rimm EB, Hankinson SE, Curhan G, Manson JE, et al. Multivariate assessment of lipid parameters as predictors of coronary heart disease among postmenopausal women: Potential implications for clinical guidelines. Circulation. 2004;110(18):2824-30. [PMID: 15492318]

20. Davidson MH, Maki KC, Karp SK, Ingram KA. Management of hypercholesterolaemia in postmenopausal women. Drugs Aging. 2002;19(3):169-178. [PMID: 12027776]

21. Wassertheil-Smoller S, Shumaker S, Ockene J, Talavera GA, Greenland P, et al. Depression and cardiovascular sequelae in postmenopausal women: the Women's Health Initiative (WHI). Arch Intern Med. 2004;164(3):289-98. [PMID: 14769624]

22. Whang W, Kubzansky LD, Kawachi I, Rexrode KM, Kroenke CH, et al. Depression and risk of sudden cardiac death and coronary heart disease in women: Results from the nurses' health study. J Am Coll Cardiol. 2009;53(11):950-8. [PMID: 19281925]

23. Shah AJ, Veledar E, Hong Y, Bremner JD, Vaccarino V. Depression and history of attempted suicide as risk factors for heart disease mortality in young individuals. Arch Gen Psychiatry. 2011;68(11):1135-42. [PMID: 22065529]

24. Xu X, Bao H, Strait K, Spertus JA, Lichtman JH, et al. Sex differences in perceived stress and early recovery in young and middle-aged patients with acute myocardial infarction. Circulation. 2015;131(7):614-23. [PMID: 25679303]

25. Albert CM, Chae CU, Grodstein F, Rose LM, Rexrode KM, et al. Prospective study of sudden cardiac death among women in the United States. Circulation. 2003;107(16):2096-101. [PMID:12695299]

26. Balady GJ, Williams MA, Ades PA, Bittner V, Comoss P, et al. Core components of cardiac rehabilitation/secondary prevention programs: 2007 update a scientific statement from the American Heart Association Exercise, Cardiac Rehabilitation and Prevention Committee, the Council on Clinical Cardiology; the Councils on Cardiovascular Nursing, Epidemiology and Prevention, and Nutrition, Physical Activity, and Metabolism; and the American Association of Cardiovascular and Pulmonary Rehabilitation. Circulation. 2007;115(20):2675-82. [PMID: 17513578]

27. Rose M, Timmons SM, Amerson, R, Reimels, E, Pruitt RH. Facilitators and barriers in cardiac rehabilitation participation: An integrative review. J Nurse Pract., 2011;7(5):399-408. DOI: 10.1016/j.nurpra.2011.02.003

28. American Association of Cardiovascular \& Pulmonary Rehabilitation. Guidelines for Cardiac Rehabilitation and Secondary Prevention Programs, 5e. Champaign, IL: Human Kinetics; 2013.

29. Antman EM, Anbe DT, Armstrong PW, Bates ER, Green LA, et al. ACC/AHA Guidelines for the management of patients With ST-elevation myocardial infarction-Executive summary: A report of the American College of Cardiology/American Heart Association Task Force on practice guidelines (Writing Committee to Revise the 1999 Guidelines for the Management of Patients With Acute Myocardial Infarction). J Am Coll Cardiol. 2004;44(3):671-719. [PMID: 15358045]

30. Gibbons RJ, Abrams J, Chatterjee K, Daley J, Deedwania PC, et al. ACC/AHA 2002 guideline update for the management of patients with chronic stable angina-summary article: A report of the American College of Cardiology/American Heart Association Task Force on practice guidelines (Committee on the Management of Patients with Chronic Stable Angina). $J$ Am Coll Cardiol. 2003;41(1):159-68. [PMID: 12570960]

31. Leon AS, Franklin BA, Costa F, Balady GJ, Berra KA, et al. Cardiac rehabilitation and secondary prevention of coronary heart disease: An American Heart Association scientific statement from the Council on Clinical Cardiology (Subcommittee

(C) The Internet Journal of Allied Health Sciences and Practice, 2017 
on Exercise, Cardiac Rehabilitation, and Prevention) and the Council on Nutrition, Physical Activity, and Metabolism (Subcommittee on Physical Activity), in collaboration with the American Association of Cardiovascular and Pulmonary Rehabilitation. Circulation. 2005;111(3):369-76. [PMID: 15668354]

32. Piepoli MF, Corra U, Benzer W, Bjarnason-Wehrens B, Dendale P, et al. Secondary prevention through cardiac rehabilitation: From knowledge to implementation. A position paper from the Cardiac Rehabilitation Section of the European Association of Cardiovascular Prevention and Rehabilitation. Eur J Prev Cardiol. 2010;17(1):1-17. [PMID: 19952757]

33. Wenger NK, Froelicher ES, Smith LK, Philip A. Ades PA, et al. Clinical Practice Guidelines No. 17: Cardiac Rehabilitation as Secondary Prevention. Rockville, Md: US Department of Health and Human Services, Public Health Service, Agency for Health Care Policy and Research, National Heart, Lung and Blood Institute;1995. AHCPR Publication 96-0672.

34. Clark AM, Hartling L, Vandermeer B, McAlister FA. Meta-analysis: Secondary prevention programs for patients with coronary artery disease. Ann Intern Med. 2005;143(9):659-72. [PMID:16263889]

35. Mosca L, Banka CL, Benjamin EJ, Berra K, Bushnell C, et al. Evidence-based guidelines for cardiovascular disease prevention in women: 2007 update. J Am Coll Cardiol. 2007;49(11):1230-50. [PMID:17309915]

36. Oldridge N. Exercise-based cardiac rehabilitation in patients with coronary heart disease: Meta-analysis outcomes revisited. Future Car. 2012;8(5):729-51. [PMID: 23013125]

37. Anderson L, Oldridge N, Thompson DR, Zwisler A, Rees K, Martin N, Taylor RS. Exercise-based cardiac rehabilitation for coronary heart disease: Cochrane systematic review and meta-analysis. J Am Coll Cardiol. 2016;67(1):1-12. [PMID: 26764059]

38. Hammonds TL, Gathright EC, Goldstein CM, Penn MS, Hughes JW. Effects of exercise on c-reactive protein in healthy patients and in patients with heart disease: A meta-analysis. Heart Lung. 2016;45(3):273-82. [PMID: 27664312]

39. Lavie CJ, Milani RV. Adverse psychological and coronary risk profiles in young patients with coronary artery disease and benefits of formal cardiac rehabilitation. Arch Intern Med. 2006;166(17):1878-83. [PMID: 17000945]

40. Lavie CJ, Milani RV, Lavie TJ. Impact of cardiac rehabilitation, exercise training, and fitness on psychological distress. In Sher L (Ed.). Psychological Factors and Cardiovascular Disorders: The Role of Stress and Psychosocial Influences, 31229. New York, NY: Nova Science Publisher, Inc; 2009

41. Milani RV, Lavie CJ, Cassidy MM. Effects of cardiac rehabilitation and exercise training programs on depression in patients after major coronary events. Am Heart J. 1996;132(4):726-32. [PMID: 8831359]

42. Brown J, Clark AM, Dalal H, Welch K, Taylor RS. Patient education in the management of coronary heart disease. Cochrane Database Syst Rev. 2011;12. Retrieved from http://dx.doi.org/doi:10.1002/14651858.CD008895.pub2_[PMID: 22161440]

43. Whalley B, Rees K, Davies $P$, Bennett $P$, Ebrahim S, et al. Psychological interventions for coronary heart disease. Cochrane Database Syst Rev. 2011;(8):CD002902 [PMID: 21833943]

44. Taylor RS, Brown A, Ebrahim S, Jolliffe J, Noorani H, et al. Exercise-based rehabilitation for patients with coronary heart disease: Systematic review and meta-analysis of randomized controlled trials. The Am J Med. 2004;116(10):682-92. [PMID: 15121495]

45. Levin L, Perk J, Hedbäck B. Cardiac rehabilitation—a cost analysis. J Intern Med. 1991;230(5):427-34. [PMID: 1940778]

46. Oldridge N, Furlong W, Feeny D, Torrance G, Guyatt G, Crowe J, Jones N. Economic evaluation of cardiac rehabilitation soon after acute myocardial infarction. Am. J Cardiol. 1993;72(2):154-61. doi.org/10.1016/0002-9149(93)90152-3

47. Colbert JD, Martin BJ, Haykowsky MJ, Hauer TL, Austford LD, et al. Cardiac rehabilitation referral, attendance, and mortality in women. Eur J Prev Cardiol. 2015;22(8):979-86. DOI: https://doi.org/10.1177/2047487314545279

48. Colella TJ, Gravely S, Marzolini S, Grace SL, Francis JA, Oh P, Scott LB. Sex bias in referral of women to outpatient cardiac rehabilitation? A meta-analysis. Eur J Prev Cardiol. 2015;22(4):423-41. [PMC 4592377]

49. Oosenbrug E, Marinho RP, Zhang J, Marzolini S, Colella TJ, et al.. Sex differences in cardiac rehabilitation adherence: A meta-analysis. Can J Cardiol. 2016;32(11):1316-1324 [ PMID: 27129618]

50. Samayoa L, Grace SL, Gravely S, Scott LB, Marzolini S, Colella TJF. Sex differences in cardiac rehabilitation enrollment: A meta-analysis. Can J Cardiol. 2014;30(7):793-800. [PMID: 24726052]

51. Clark AM, King-Shier KM, Spaling MA, Duncan AS, Stone JA, et al. Factors influencing participation in cardiac rehabilitation programmes after referral and initial attendance: Qualitative systematic review and meta-synthesis. Clin Rehabil. 2013;27(10):948-59. [PMID: 23798748]

52. Daly J, Sindone AP, Thompson DR, Hancock K, Chang E, Davidson P. Barriers to participation in and adherence to cardiac rehabilitation programs: A critical literature review. Prog Cardiovasc Nurs. 2002;17(1):8-17. [PMID: 11872976]

53. Casey E, Hughes JW, Waechter D, Josephson R, Rosneck J. Depression predicts failure to complete phase-II cardiac rehabilitation. J Behav Med. 2008;31(5):421-31. [PMID: 18719990]

54. Marzolini S, Brooks D, Oh PI. Sex differences in completion of a 12-month cardiac rehabilitation programme: An analysis of 5922 women and men. Eur. J. Prev. Cardiol . 2008;15(6):698-703. DOI: https://doi.org/10.1177/1741826710393197

55. Sanderson BK, Phillips MM, Gerald L, DiLillo V, Bittner V. Factors associated with the failure of patients to complete cardiac rehabilitation for medical and nonmedical reasons. J Cardiopulm Rehabil Prev. 2003;23(4):281-9. [PMID: 12894002]

(c) The Internet Journal of Allied Health Sciences and Practice, 2017 
56. Cooper AF, Jackson G, Weinman J, Horne R. Factors associated with cardiac rehabilitation attendance: A systematic review of the literature. Clin Rehabil. 2002;16(5):541-52. [PMID: 12194625]

57. Thomas RJ, Miller NH, Lamendola C, Berra K, Hedbäck B, et al. National survey on gender differences in cardiac rehabilitation programs: Patient characteristics and enrollment patterns. J Cardiopulm Rehabil Prev. 1996;16(6):402-12. [PMID: 17903645]

58. Worcester MU, Murphy BM, Mee VK, Roberts SB, Goble AJ. Cardiac rehabilitation programmes: Predictors of nonattendance and drop-out. Eur J Cardiovasc Nurs. 2004;11(4):328-35. [PMID: 15292767]

59. Farley RL, Wade TD, Birchmore L. Factors influencing attendance at cardiac rehabilitation among coronary heart disease patients. Eur J Cardiovasc Nurs. 2003;2(3):205-12. [PMID: 14622628]

60. Conn V, Taylor SG, Abele PB. Myocardial infarction survivors: Age and gender differences in physical health, psychosocial state, and regimen adherence. J Adv Nurs. 1991;16(9):1026-34. [PMID: 1939915]

61. Grace SL, Gravely-Witte S, Kayaniyil S, Brual J, Suskin N, Stewart DE. A multisite examination of sex differences in cardiac rehabilitation barriers by participation status. J Women's Health. 2009;18(2):209-16. [PMCID: PMC2927522]

62. King KM, Humen DP, Smith HL, Phan CL,Teo KK. Predicting and explaining cardiac rehabilitation attendance. The Can J Cardiol. 2001;17(3):291-6. [PMID: 11264562]

63. King KM, Humen DP, Smith HL, Phan CL, Teo KK. Psychosocial components of cardiac recovery and rehabilitation attendance. Heart. 2001;85(3):290-4. [PMID: 11179268]

64. Benz Scott LA, Ben-Or K, Allen JK. Why are women missing from outpatient cardiac rehabilitation programs? A review of multilevel factors affecting referral, enrollment, and completion. J Women's Health. 2002;11(9):773-91. [PMID: 12632591]

65. Halm M, Penque S, Doll N, Beahrs M. Women and cardiac rehabilitation: Referral and compliance patterns. J Cardiovasc Nurs. 1999;13(3):83-92. [PMID: 10098008]

66. Suaya JA, Shepard DS, Normand SL, Ades PA, Prottas J, Stason WB. Use of cardiac rehabilitation by Medicare beneficiaries after myocardial infarction or coronary bypass surgery. Circulation. 2007;116(15):1653-62. [PMID: 17893274]

67. Ades PA, Waldmann ML, McCann WJ, Weaver SO. Predictors of cardiac rehabilitation participation in older coronary patients. Arch Intern Med, 1992;152(5);1033-5. [PMID: 1580707]

68. Audelin MC, Savage PD, Ades PA. Changing clinical profile of patients entering cardiac rehabilitation/secondary prevention programs: 1996 to 2006. J Cardiopulm Rehabil Prev. 2008;28(5):299-306. doi: 10.1097/01.HCR.0000336139.48698.26

69. Evenson KR, Rosamond WD, Luepker RV. Predictors of outpatient cardiac rehabilitation utilization: The Minnesota heart survey registry. J Cardiopulm Rehabil Prev. 1998;18(3):192-8. [PMID: 9632320]

70. Beckie TM, Mendonca MA, Fletcher GF, Schocken DD, Evans ME, Banks SM. Examining the challenges of recruiting women into a cardiac rehabilitation clinical trial. J Cardiopulm Rehabil Prev. 2009;29(1):13-21. [PMID: 19158582]

71. Caulin-Glaser T, Maciejewski PK, Snow R, LaLonde M, Mazure C. Depressive symptoms and sex affect completion rates and clinical outcomes in cardiac rehabilitation. Preventive Cardiology. 2007;10(1):15-21. [PMID: 17215628]

72. Turner SC, Bethell HJ, Evans JA, Goddard JR, Mullee MA. Patient characteristics and outcomes of cardiac rehabilitation. J Cardiopulm Rehabil Prev. 2002;22(4):253-60. [PMID: 12202845]

73. Balady GJ, Ades PA, Bittner VA, Franklin BA, Gordon NF, et al. Referral, enrollment, and delivery of cardiac rehabilitation/secondary prevention programs at clinical centers and beyond: A Presidential Advisory from the American Heart Association. Circulation. 2011;124(25):2951-60. [PMID: 22082676]

74. Thomas RJ, King M, Lui K, Oldridge N, Piña IL, et al. AACVPR/ACC/AHA 2007 performance measures on cardiac rehabilitation for referral to and delivery of cardiac rehabilitation/secondary prevention services endorsed by the American College of Chest Physicians, American College of Sports Medicine, American Physical Therapy Association, Canadian Association of Cardiac Rehabilitation, European Association for Cardiovascular Prevention and Rehabilitation, InterAmerican Heart Foundation, National Association of Clinical Nurse Specialists, Preventive Cardiovascular Nurses Association, and the Society of Thoracic Surgeons. J Am Coll Cardiol. 2007;50(14):1400-33. [PMID:17903645]

75. Fischer JP. Automatic referral to cardiac rehabilitation. J Cardiovasc Nurs. 2008;23(6):474-9. [PMID: 18953208]

76. Cortés $\mathrm{O}$, Arthur HM. Determinants of referral to cardiac rehabilitation programs in patients with coronary artery disease: $\mathrm{A}$ systematic review. Am Heart J. 2006;151(2):249-56. [PMID: 16442885]

77. King KM, Teo KK. Cardiac rehabilitation referral and attendance: Not one and the same. Rehabilitation Nursing. 1998;23(5):246-51. [PMID: 10067639]

78. Grace SL, Chessex C, Arthur H, Chan S, Cyr C, et al. Systematizing inpatient referral to cardiac rehabilitation 2010: Canadian Association of Cardiac Rehabilitation and Canadian Cardiovascular Society Joint Position Paper: Endorsed by the Cardiac Care Network of Ontario. Can J Cardiol. 2011;27(2):192-9. [PMID: 21459268]

79. Wenger NK. Current status of cardiac rehabilitation. J Am Coll Cardiol. 2008;51(17):1619-31. [PMID: 18436113]

80. Dalal HM, Zawada A, Jolly K, Moxham T, Taylor RS. Home based versus centre based cardiac rehabilitation: Cochrane systematic review and meta-analysis. BMJ. 2010;340:b5631. [PMID: 20085991]

(c) The Internet Journal of Allied Health Sciences and Practice, 2017 
81. Rawstorn JC, Gant N, Direito A, Beckmann C, Maddison R. Telehealth exercise-based cardiac rehabilitation: A systematic review and meta-analysis. Heart.. 2016;102:1183-92 [PMID: 26936337]

82. Taylor RS, Dalal H, Jolly K, Zawada A, Dean SG, et al. Home-based versus centre-based cardiac rehabilitation. Cochrane Database Syst Rev. 2015;Aug 18;(8):CD007130. [PMID: 26282071]

83. Neubeck L, Lowres, N, Benjamin EJ, Freedman SB, Coorey G, Redfern J. The mobile revolution-using smartphone apps to prevent cardiovascular disease. Nat Rev Cardiol. 2015;12(6):350-60. [PMID: 25801714]

84. Varnfield M, Karunanithi M, Lee CK, Honeyman E, Arnold D, et al. Smartphone-based home care model improved use of cardiac rehabilitation in postmyocardial infarction patients: Results from a randomised controlled trial. Heart. 2014;100(22):1770-9. [PMID: 24973083]

85. Turk-Adawi K, Grace SL. Smartphone-based cardiac rehabilitation. Heart. 2014;100(22):1737-8. [PMID: 25163694]

86. Grace SL, McDonald J, Fishman D, Caruso V. Patient preferences for home-based versus hospital-based cardiac rehabilitation. J Cardiopulm Rehabil Prev. 2005;25(1):24-9. [PMID: 15714108]

87. Karmali KN, Davies P, Taylor F, Beswick A, Martin N, Ebrahim S. Promoting patient uptake and adherence in cardiac rehabilitation. Cochrane Database Syst Rev. 2014;6. Retrieved from http://dx.doi.org/doi:10.1002/14651858.CD007131.pub3 [PMID: 24963623]

88. Benson G, Arthur H, Rideout E. Women and heart attack: A study of women's experiences. Can J Cardiovasc Nurs. 1997; 8(3);16-23. [PMID: 9416023]

89. Bjarnason-Wehrens $\mathrm{B}$, Grande $\mathrm{G}$, Loewe, $\mathrm{H}$, Voller H, Mittag $\mathrm{O}$. Gender-specific issues in cardiac rehabilitation: Do women with ischaemic heart disease need specially tailored programmes? Eur J Cardiovasc Prev Rehabil. 2007;14(2):163-71. [PMID: 17446793]

90. Davidson P, Digiacomo M, Zecchin R, Clarke M, Paul G, et al. A cardiac rehabilitation program to improve psychosocial outcomes of women with heart disease. J Women's Health. 2008;17(1):123-34. [PMID: 18240989]

91. Davidson PM, Daly J, Hancock K, Moser D, Chang E, Cockburn J. Perceptions and experiences of heart disease: A literature review and identification of a research agenda in older women. Eur J Cardiovasc Nurs. 2003;2(4):255-64. [PMID:14667481]

92. Price J. A pilot trial of a coaching intervention designed to increase women's attendance at cardiac rehabilitation intake (Doctoral dissertation, University of Toronto), 2012. Available from https://tspace.library.utoronto.ca/bitstream/1807/34854/1/Price_Jennifer_AD_201211_PhD_thesis.pdf. Accessed January 2, 2017.

93. Bandura A. Social cognitive theory: An agentic perspective. Annu Rev Psychol. 2001;52(1):1-26. DOI: 10.1146/annurev.psych.52.1.1

94. Bandura A. Social Foundations of Thought and Action: A Social Cognitive Theory. Englewood Cliffs, NJ: Prentice-Hall; 1986.

95. Beckie TM. A behavior change intervention for women in cardiac rehabilitation. J Cardiovasc Nurs. 2006;21(2):146-53. [PMID: 16601534]

96. Prochaska JO, Velicer WF. The Transtheoretical Model of health behavior change. Am J Health Promot. 1997;12(1):3848. [PMID: 10170434]

97. Miller WR, Rollnick S. Motivational Interviewing: Preparing People for Change, 2e. New York, NY: Guilford Press; 2002.

98. Prochaska JO, DiClemente CC, Norcross JC. In search of how people change: Applications to addictive behaviors. Am Psychol. 1992;47(9);1102-14. [PMID: 1329589]

99. Velicer WF, Norman GJ, Fava JL, Prochaska JO. Testing 40 predictions from the Transtheoretical model. Addict Behav. 1999;24(4):455-69. [PMID: 10466842]

100. Prochaska JO, Velicer WF, Redding C, Rossi JS, Goldstein M, et al. Stage-based expert systems to guide a population of primary care patients to quit smoking, eat healthier, prevent skin cancer, and receive regular mammograms. Prev Med. 2005;41(2);406-16. [PMID: 15896835]

101. Beckie TM. Referral, enrollment, and delivery of cardiac rehabilitation for women. Curr Cardiovasc Risk Rep. 2012;6(5):45968. [PMID: 2995341]

102. Bruce EH, Frederick R, Bruce RA, Fisher R. Comparison of active participants and dropouts in CAPRI cardiopulmonary rehabilitation programs. Am J Cardiol. 1976;37:53-60

103. Shaw DK, Sparks KE, Jennings HS, III. Transtelephonic exercise monitoring: a review. J Cardiopul Rehabil. 1998;18(4):263-70. [PMID: 9702604] 